\title{
Calcination Temperature Reflected Structural, Optical and Magnetic Properties of Nickel Oxide
}

\author{
Sonam Dwivedi ${ }^{1}$, Hari Chandra Nayak ${ }^{1}$, Shivendra Singh Parmar ${ }^{2}$, Rajendra Prasad Kumhar ${ }^{1}$ and \\ Shailendra Rajput ${ }^{3, * \text { (D) }}$
}

check for updates

Citation: Dwivedi, S.; Nayak, H.C.; Parmar, S.S.; Kumhar, R.P.; Rajput, S. Calcination Temperature Reflected Structural, Optical and Magnetic Properties of Nickel Oxide. Magnetism 2022, 2, 45-55. https://doi.org/10.3390/ magnetism 2010004

Received: 2 November 2021 Accepted: 2 February 2022

Published: 16 February 2022

Publisher's Note: MDPI stays neutral with regard to jurisdictional claims in published maps and institutional affiliations.

Copyright: (C) 2022 by the authors. Licensee MDPI, Basel, Switzerland. This article is an open access article distributed under the terms and conditions of the Creative Commons Attribution (CC BY) license (https:// creativecommons.org/licenses/by/ $4.0 /)$.
1 Department of Physics, Maharaja Chhatrasal Bundelkhand University, Chhatarpur 471001, India; sonam.dwivedi88@gmail.com (S.D.); drhc.nayak@mp.gov.in (H.C.N.); drrajendrap.kumhar@mp.gov.in (R.P.K.)

2 Department of Chemistry, Shri Krishna University, Chhatarpur 471001, India; shivendraparmarofficial@gmail.com

3 Department of Electrical and Electronic Engineering, Ariel University, Ariel 40700, Israel

* Correspondence: shailendrara@ariel.ac.il; Tel.: +91-7240878258

\begin{abstract}
Stoichiometric compositions of $\mathrm{NiO}$ were prepared by the standard chemical co-precipitation method to inspect the effect of the calcination temperature on structures, morphology, and physical properties. The samples were calcined at three different temperatures viz. $350{ }^{\circ} \mathrm{C}, 550{ }^{\circ} \mathrm{C}$, and $650{ }^{\circ} \mathrm{C}$ for $5 \mathrm{~h}$. X-ray diffraction analysis confirmed the cubic $(\mathrm{Fm}-3 \mathrm{~m})$ structure of the prepared samples. The average crystalline size increases from $41 \mathrm{~nm}$ to above $100 \mathrm{~nm}$ as the calcination temperature increases in the same time period. In Fourier transform infrared spectra, the spectral absorption bands were observed at 413,434 , and $444 \mathrm{~cm}^{-1}$. The bandgap energy of $\mathrm{NiO}$ particles is decreased from $3.6 \mathrm{eV}$ to $3.41 \mathrm{eV}$ as the calcination temperature increases. The magnetic analysis confirms that the magnetization value of $\mathrm{NiO}$ is invariably decreased with a rise in the calcination temperature.
\end{abstract}

Keywords: nickel oxide; ceramics; material characterization; optical properties; bandgap engineering

\section{Introduction}

Theory and experimental advances in ferromagnetic semiconductors offer anticipation for a new generation of microelectronic devices. In recent days, nanoscale ferromagnetic semiconductor oxides are gaining significant attention for various potential applications, such as spin-polarized carrier sources, a catalyst for oxygen evolution, and easy integration into semiconductor technology [1-3]. The study of small particles has become of increasing interest due to the new properties in those materials shown when the crystal size is reduced.

Nickel oxide (NiO) in bulk form, crystallized in rhombohedral structure with space group $\mathrm{R} 3 \mathrm{~m}$ with antiferromagnetic ordering [4]. NiO nanoparticles-a NaCl-type cubic crystalline structure (space group, Fm3m) antiferromagnetic semiconductor-are a transition metal oxide of great interest due to its magnetic properties [5,6] and well dispersion, and are desirable for many applications in designing ceramic, magnetic, and heterogeneous catalytic materials [7]. It was found that the critical annealing temperature for $\mathrm{NiO}$ nanoparticles in the air and oxygen atmospheres is $\sim 60{ }^{\circ} \mathrm{C}[8,9]$.

To prepare $\mathrm{NiO}$ nanoparticles, various synthesis methods were adopted earlier, such as sol-gel [10], impregnation [11], spray pyrolysis [12], microwave [13], oxidation [14], coprecipitation [15], sonochemistry [16], and ion exchange [17]. Some of the above methods suffer from the difficulty in size-homogeneity and well dispersion of $\mathrm{NiO}$ nanoparticles. To obtain better properties of $\mathrm{NiO}$, the synthesis conditions must be well controlled to obtain particularly fine powders with a narrow particle size distribution that enhance the performance of materials. It has been reported that $\mathrm{NiO}$ nanoparticles show hysteresis below a blocking temperature, irreversibility between the field cooled and zero field cooled magnetization curves [18,19], large coercivities [20], weak ferromagnetism and 
superparamagnetism, and spin-glass behavior [21,22]. It is found that the calcination temperature significantly affects the characteristic properties of $\mathrm{NiO}[23,24]$. The magnetic properties of the nanostructured nickel oxide are found to be markedly different from those of single-crystalline [23]. It was reported that the increase in calcination temperature resulted in an increase in particle size with a high surface area [25]. Understanding the size-dependent magnetization is not only important for practical applications but also it is of great interest to identify the unprecedented nature of the antiferromagnetic oxide nanostructures between the structure and properties [26].

Motivated through the above, in the present work, we investigate the effect of different calcination temperatures on the structural, optical, and magnetic properties of $\mathrm{NiO}$ particles. We have used the chemical co-precipitation method to synthesize the $\mathrm{NiO}$ particles. Furthermore, the grown materials were characterized by X-ray powder diffraction (XRD), scanning electron microscopy (SEM), Raman spectroscopy, Fourier transform infrared (FTIR) spectroscopy, X-ray photoelectron spectroscopy, UV-Vis spectroscopy, and magnetic measurement.

\section{Materials and Methods}

The chemical co-precipitation method was used for the synthesis of polycrystalline $\mathrm{NiO}$ samples using a high purity compound of $\mathrm{Ni}\left(\mathrm{NO}_{3}\right)_{2} \cdot 6 \mathrm{H}_{2} \mathrm{O}$. In order to prepare aqueous solutions of nickel salt, $10 \mathrm{gm}$ of $\mathrm{Ni}\left(\mathrm{NO}_{3}\right)_{2} \cdot 6 \mathrm{H}_{2} \mathrm{O}$ were dissolved in $500 \mathrm{~mL}$ of distilled water. This aqueous solution was freshly prepared in an appropriate molar ratio. After that, the solution was kept at $80{ }^{\circ} \mathrm{C}$ and $6 \mathrm{M} \mathrm{NaOH}$ was added to the solution. As a result, the $\mathrm{pH}$ value of the solution rapidly increased to 12 . The particles settled at the bottom were collected and the top water layer with excess salts was discarded. The particles were washed repeatedly with distilled water to remove salt impurities. Later on, the washed particles were dried at room temperature and calcined at different temperatures for $5 \mathrm{~h}$. The synthesized samples of $\mathrm{NiO}$ with different calcination temperatures, such as $350{ }^{\circ} \mathrm{C}, 550{ }^{\circ} \mathrm{C}$, and $650{ }^{\circ} \mathrm{C}$ for $5 \mathrm{~h}$ were further designated as $\mathrm{N}-1, \mathrm{~N}-2$, and $\mathrm{N}-3$, respectively

Phase purity and crystal structure of the samples at room temperature were identified using a Bruker D8 Advance X-ray diffractometer. The X-ray diffraction (XRD) data were collected for the range $20^{\circ}<2 \theta<80^{\circ}$ with a step size of 0.02 and scanning speed of $2^{\circ}$ per $50 \mathrm{~s}$. The $X$-rays were produced $(40 \mathrm{kV}$ and $40 \mathrm{~mA})$ using a sealed tube and the wavelength of the X-ray was $1.5406 \AA(\mathrm{CuK} \alpha)$. The surface morphology and microstructure of the grown ceramics were studied with a scanning electron microscope (SEM) (LEO 430 electron microscope Polaron SC7640 Sputter Coater (gold palladium)). Raman measurements on as-synthesized samples were carried out on a Jobin-Yovn Horiba Labram (System HR800) spectrometer with a $488 \mathrm{~nm}$ excitation source equipped with a Peltier cooled charge-coupled device detector. Fourier transform infrared (FT-IR) spectra were recorded in the frequency range of $4000-400 \mathrm{~cm}^{-1}$ employing the $\mathrm{KBr}$ pellets technique using Bruker Germany make spectrometer model vertex-70. Furthermore, XPS measurements on the samples were carried out using a VSW ESCA machine equipped with AlK $\alpha$ radiation. The diffuse reflectance spectra of grown samples were measured using the UVVis spectrometer (Perkin Elmer, Lambda 950, Waltham, MA, USA). The bandgap energy was calculated from the diffuse reflection spectra according to the Kubelka-Munk theory. The magnetization measurements were performed using a vibrating sample magnetometer (VSM-magnetic analyzer).

\section{Results and Discussion}

\subsection{Structural and Microstructural Properties}

Figure 1 shows the XRD patterns of N-1, N-2, and N-3 samples. The peaks' positions appearing at $2 \theta$ is $37.21^{\circ}, 43.22^{\circ}, 63.10^{\circ}, 75.20^{\circ}$, and $79.39^{\circ}$ can be readily indexed as (111), (200), (220), (311), and (222) crystal planes of the $\mathrm{NiO}$, respectively. The main peaks are comparable to that of the standard powder diffraction spectrum of NiO (JCPDS card No. 78-0429) and those reported in the literature for cubic NiO [27,28]. The XRD 
pattern shows that the samples are single phase and no other impurities distinct from the diffraction peak except the characteristic peaks of FCC phase NiO were detected. The diffraction peaks are indexed in the cubic phase of $\mathrm{NiO}$ with space group $\mathrm{Fm}-3 \mathrm{~m}$. Structural analysis confirms the cubic $(F m-3 m)$ phase for all the three compounds with the lattice parameters $\left(a=b=c=4.16 \AA\right.$; $\left.\alpha=\beta=\gamma=90^{\circ}\right)$.

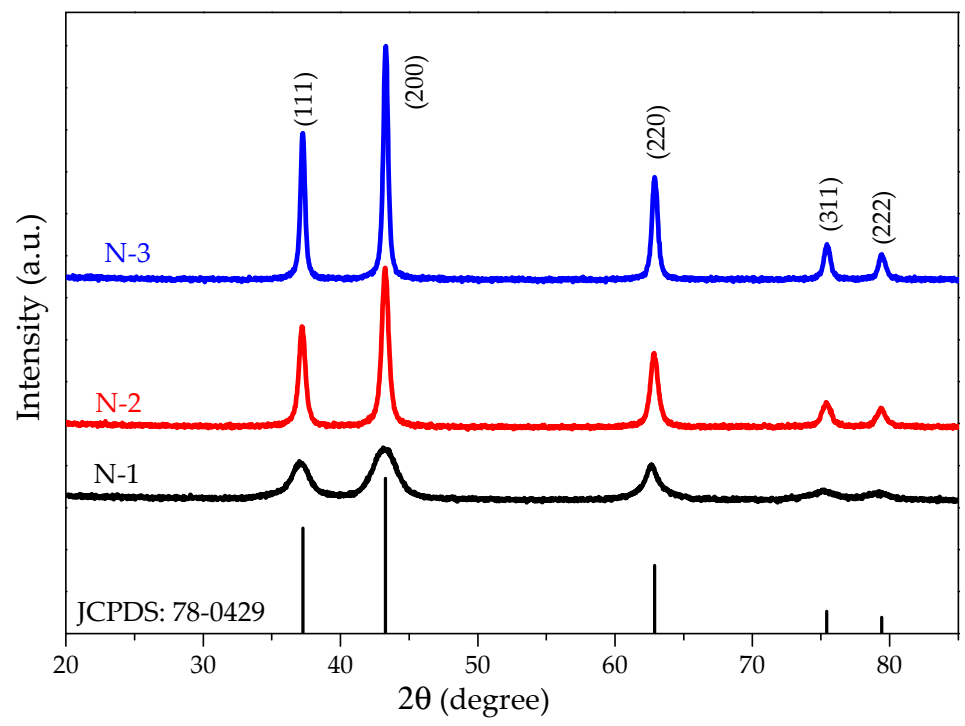

Figure 1. Room temperature XRD patterns of N-1, N-2, and N-3 samples are compared with standard powder diffraction of $\mathrm{NiO}$ (JCPDS card No. 78-0429).

It can be seen from Figure 1 that the diffraction peaks are low intense and broad at low calcination temperature. The broadening of the peaks indicated that the particles were of nanometer scale. The crystallite size diameter of the $\mathrm{NiO}$ sample has been determined from the broadening of the most intense peak (200) in the XRD pattern using DebyeScherrer's equation:

$$
D=\frac{0.9 \lambda}{\beta \cos \theta}
$$

where $\lambda$ is the $X$-ray wavelength, $\beta$ is the full width of the diffraction line at half its maximum intensity, and $\theta$ is the Bragg angle. The crystallite size was found to be 41,132 , $191 \mathrm{~nm}$ for N-1, N-2, and N-3, respectively. This is attributed that as we have increased the calcination temperature of the samples, crystallite size also has been increased.

Figure 2 shows the SEM images of N-1, N-2, and N-3 samples. These images reveal a systematic evaluation of the morphology of the prepared samples. For all three $\mathrm{NiO}$ samples, the images show aggregate particles. As the particles are aggregated, hence it is difficult to do a size distribution analysis. It is observed that the particles are sphericalshaped nanocrystallites. Previously, it was reported that the crystallite size was found to increase with increasing calcination temperatures [24,25]. 

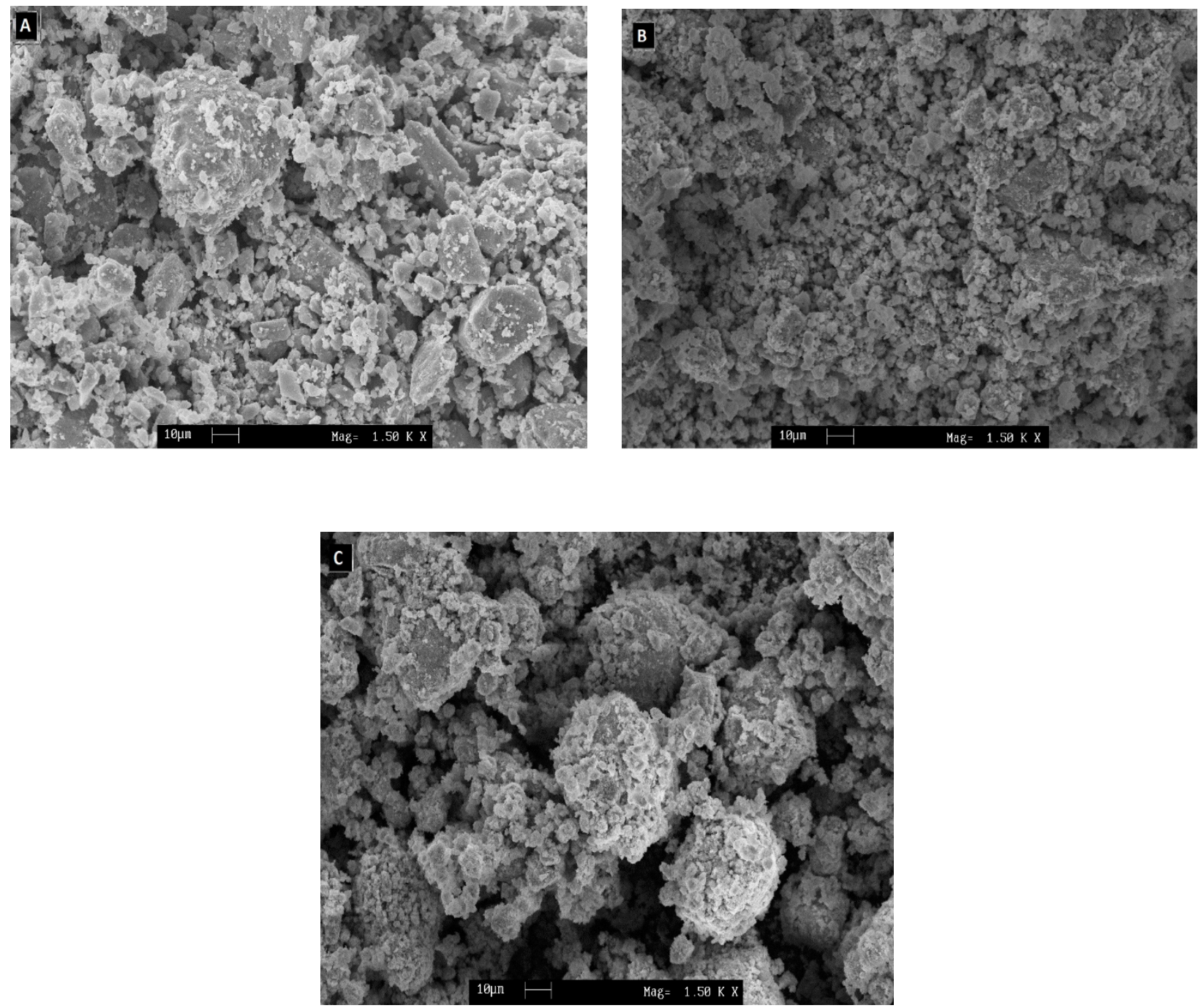

Figure 2. SEM micrograph of $\mathrm{NiO}$ calcined at a temperature of $(\mathbf{A}) 350^{\circ} \mathrm{C}$, (B) $550{ }^{\circ} \mathrm{C}$, and $(\mathbf{C}) 650{ }^{\circ} \mathrm{C}$.

\subsection{Raman Analysis}

Raman scattering is a useful probe to study the presence of lattice defects in solids, such as structure transition, lattice distortion, cation distribution, and magnetic ordering. The room temperature Raman spectra of pure $\mathrm{NiO}$ consists of several bands within the range of 200 to $1400 \mathrm{~cm}^{-1}$, and is shown in Figure 3. The Raman spectrum exhibited a strong, broad peak at $\sim 494-499 \mathrm{~cm}^{-1}$ due to the Ni-O stretching mode [29]. Vibration modes at around $400 \mathrm{~cm}^{-1}, 499 \mathrm{~cm}^{-1}$ were attributed to one-phonon (1P) and transverse optical (TO) mode, respectively. The frequencies of the LO modes have a blue shift $\left(494-499 \mathrm{~cm}^{-1}\right)$ with an increasing calcination temperature of nanocrystals. This phenomenon was reported previously and can be ascribed to the size-induced phonon confinement effect in corroboration with the strength of the two-phonon coupling and surface relaxation [30-32]. This confirms that the size of $\mathrm{NiO}$ nanocrystals has a strong effect on their magnetic properties. Some artifacts are seen in the Raman spectra of N-2 and N-3 samples. These changes are not related to samples and can be related to an instrumental error or some other factor. 


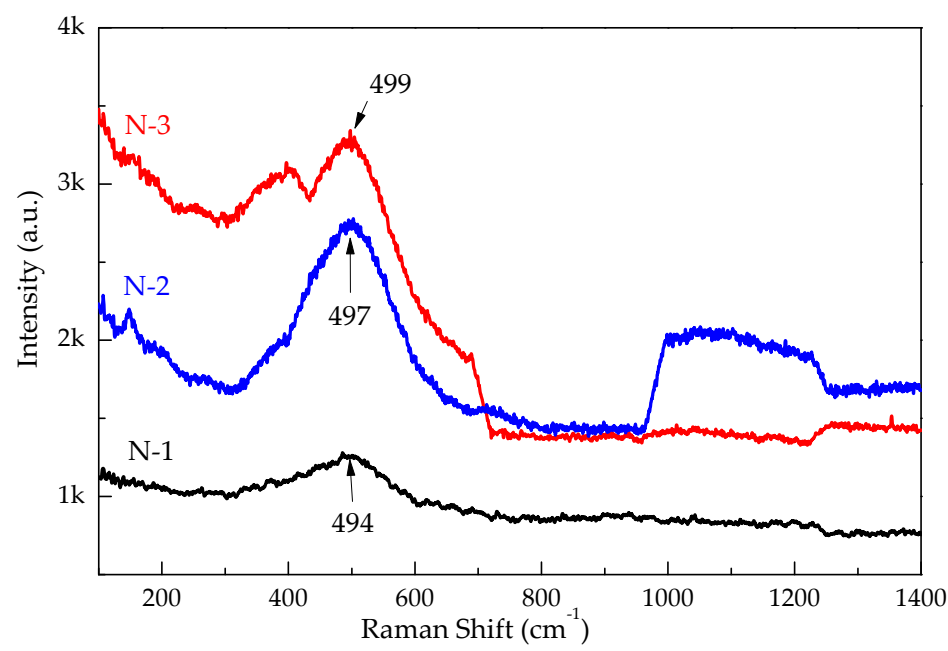

Figure 3. Raman scattering spectra of $\mathrm{N}-1, \mathrm{~N}-2$, and N-3 particles carried out at room temperature.

\subsection{FT-IR Spectroscopy}

Figure 4 depicts the FT-IR spectrum of N-1, N-2, and N-3 nanomaterials in the range of mid-IR. The broad absorption peak at about $3446 \mathrm{~cm}^{-1}$ is attributed to the $\mathrm{O}-\mathrm{H}$ stretching vibration of interlayer water molecules and $\mathrm{H}$-bound of $\mathrm{OH}$ group and the band near $1621 \mathrm{~cm}^{-1}$ is assigned to $\mathrm{H}-\mathrm{O}-\mathrm{H}$ bending vibrations. The band at $1384 \mathrm{~cm}^{-1}$ is the characteristic of $\mathrm{NO}^{3-}$ interlayer $[33,34]$. The small presence of nitrates in the samples may worsen the characteristic behavior of $\mathrm{NiO}$. The IR band at $1708 \mathrm{~cm}^{-1}$ can be related to $\mathrm{NaNO}_{3}$ as a by-product of the reaction. The bands at 2923 and $2851 \mathrm{~cm}^{-1}$ are due to C-H vibrations which were incorporated during the calcinations process [35]. The spectrum of the N-1, N-2, and N-3 calcined at different temperatures clearly shows the Ni-O absorption band near $\sim 413,434$, and $444 \mathrm{~cm}^{-1}$, respectively. These absorption bands' peak is undoubtedly assigned to $\mathrm{Ni}-\mathrm{O}$ stretching and gave clear evidence for the presence of the crystalline behavior [27].

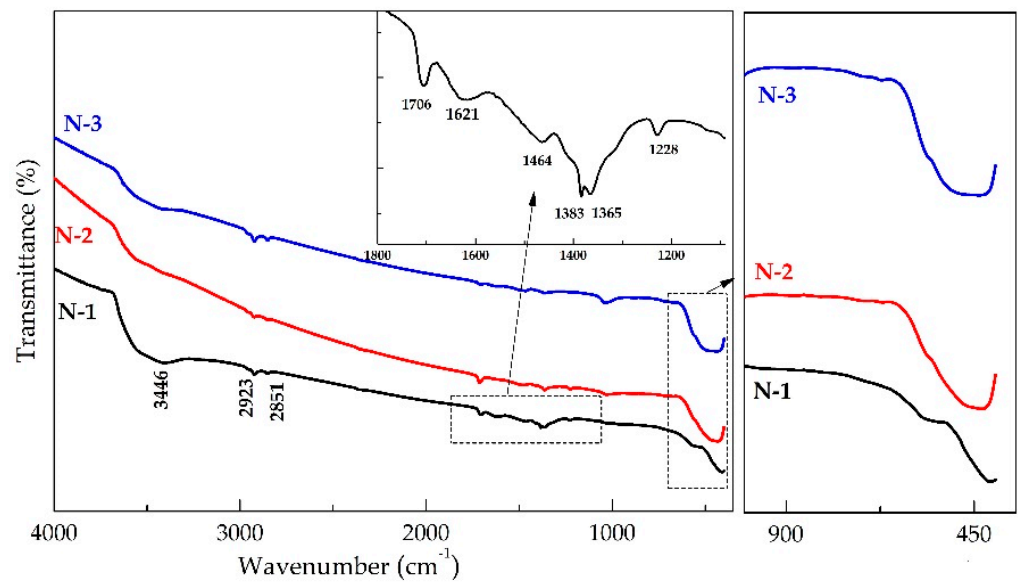

Figure 4. Fourier transforms infrared spectra of N-1, N-2, and N-3 samples. Inset shows the enlarged FT-IR spectra of the N-1 sample.

\subsection{XPS Spectroscopy}

$\mathrm{XRD}$ is a bulk technique that penetrates the entire sample volume. However, XPS is surface-sensitive, with the sampling depth determined by the kinetic energy of the photoelectron. The mean free path is $\sim 1.0-1.3 \mathrm{~nm}$ for the $\sim 400 \mathrm{eV}(\mathrm{MgK} \alpha)-633 \mathrm{eV}$ $(\mathrm{AlK} \alpha)$ kinetic energies of the Ni $2 p$ photoelectron and assuming an exponential attenuation of the photoelectron with a depth into the sample surface, $95 \%$ of the XPS signal arises from within 2.3-3.0 $\mathrm{nm}$ of the outermost surface layers of the $\mathrm{NiO}$ samples. Thus, the 
XPS technique was used to investigate the surface compositions and chemical state of the samples; X-ray photoelectron spectroscopy (XPS) measurements were performed on the $\mathrm{N}-1$ sample (calcined at $350^{\circ} \mathrm{C}$ ). The full scan of the $\mathrm{NiO}$ sample is presented in Figure 5a and performed in a range of binding energy of $0-1400 \mathrm{eV}$. The spectrum consists of a peak corresponding to $\mathrm{C}, \mathrm{O}$, and $\mathrm{Ni}$, only showing the purity of the product. The peak with $\mathrm{O} 1 \mathrm{~s}$ binding energy around $529.17 \mathrm{eV}$ corresponds to Ni-O bonds, as shown in Figure $5 \mathrm{~b}$. This indicates that the oxygen atoms existed as $\mathrm{O}^{2-}$ species in as-synthesized $\mathrm{NiO}$ compound.
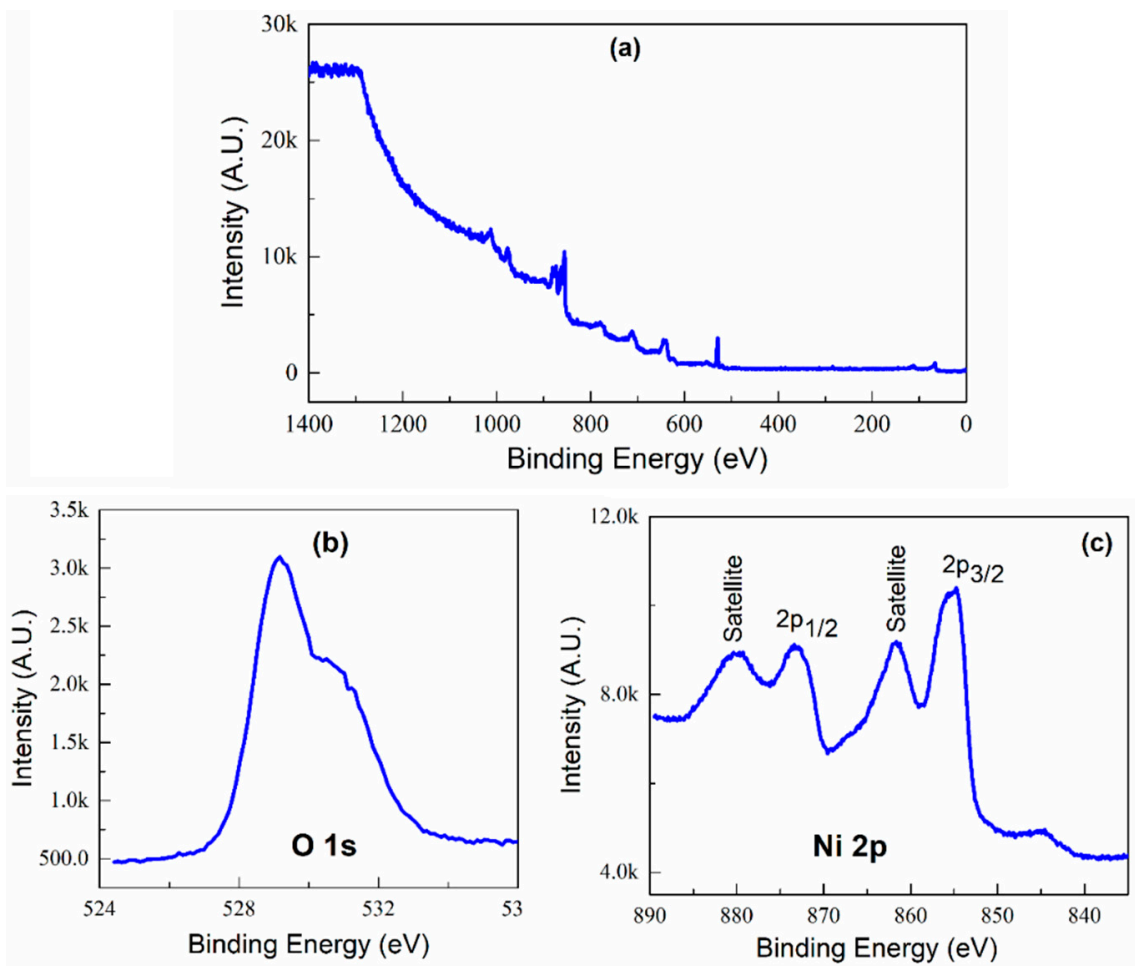

Figure 5. X-ray photoelectron spectra of $\mathrm{NiO}$ sample (a) Full scan, (b) high-resolution spectra of O1s (c) high-resolution spectra of Ni $2 p$ core level.

The Ni $2 p$ region (Figure 5 c) comprises four easily discernible features: the Ni $2 p 3 / 2$ main peak and its satellite at $\sim 854$ and $\sim 862 \mathrm{eV}$, and the Ni $2 p 1 / 2$ main peak and its satellite at $\sim 872$ and $\sim 879 \mathrm{eV}$, respectively, and is in agreement with the earlier reported value of $\mathrm{NiO}[36,37]$. No binding energy shifts or peak shape changes are observed, and contrary to other reports for similar-sized particle systems, the nanosized NiO Ni $2 p$ XPS is identical to that of well-ordered stoichiometric nickel oxide [38,39].

The structure can be analyzed in terms of a simplified model of final-state effects in which photoemission is potentially accompanied by rearrangement of electrons in the valence band:

$$
\begin{gathered}
2 p^{6} 3 d^{8}+h v \rightarrow 2 p^{5} 3 d^{8}+e^{-} \\
2 p^{6} 3 d^{8}+h v \rightarrow 2 p^{5} 3 d^{9} \underline{L}+e^{-}
\end{gathered}
$$

where $\underline{L}$ models screening by the $\mathrm{O} 2 p$ valence band and represents a hole at the $\mathrm{O} 2 p$ level. The main feature is generally assigned to the screened core hole photoemission (Equation (3)) with peak $854 \mathrm{eV}$ ascribed to local screening from lattice oxygen adjacent to the Ni $2 p$ core hole and peak $855 \mathrm{eV}$ being to nonlocal screening. The satellite region is fit to peak at $861 \mathrm{eV}$ and peak at $865 \mathrm{eV}$ and is dominated by the nonscreened mechanism of Equation (2). Evaluating the peak position and symmetry of the Ni $3 p$ line shape, one can reason that nickel was present in a $2+$ oxidation state. 


\subsection{Optical Properties}

UV-vis absorption spectroscopy is one of the important methods to reveal the energy structure and optical properties of semiconductor materials. In our measurements, the sample was analyzed through diffuse reflectance arrangement. Figure 6 shows the absorption spectra of the as-prepared $\mathrm{NiO}$ samples (i.e., $\mathrm{N}-1, \mathrm{~N}-2$, and $\mathrm{N}-3$ ) transformed from the diffuse reflection spectra according to the Kubelka-Munk (K-M) theory [40]. The energy bandgap of $\mathrm{NiO}$ particles could be estimated from the Eg measurement using Kubelka-Munk functions [41] and $F(R)$ is estimated from the following equation:

$$
F(R)=\frac{(1-R)^{2}}{2 R}
$$

where $F(R)$ is the remission or Kubelka-Munk function, where $R$ is the reflectance. A graph is plotted between $[F(R) h v]^{2}$ and $h v$, the intercept value is the bandgap energy, as shown in Figure 6. The curves indicate that the values of the direct bandgap (Eg) values are $3.60,3.57$, and $3.41 \mathrm{eV}$ for $\mathrm{N}-1, \mathrm{~N}-2$, and $\mathrm{N}-3$, respectively. It can be seen that the bandgap values clearly decrease from $3.6 \mathrm{eV}(\mathrm{N}-1)$ to $3.41 \mathrm{eV}(\mathrm{N}-3)$ with an increase in calcination temperature, which might be ascribed to the additional sub-band-gap energy levels that are induced by the abundant surface and interface defects in the agglomerated particles [42]. The bandgap value is influenced by various factors, such as crystallite size, structural parameter, carrier concentrations, presence of impurities, and lattice strain [43].
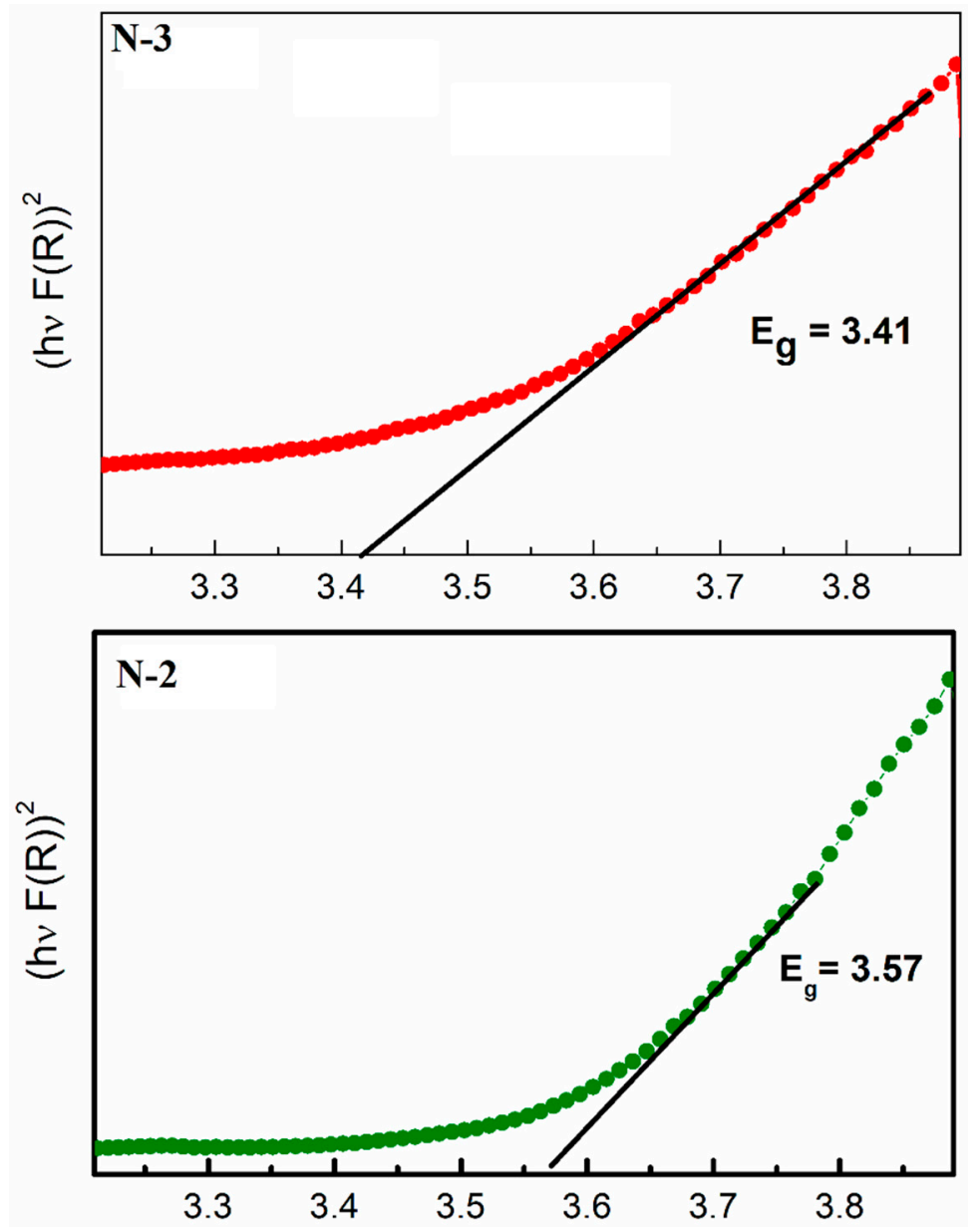

Figure 6. Cont. 


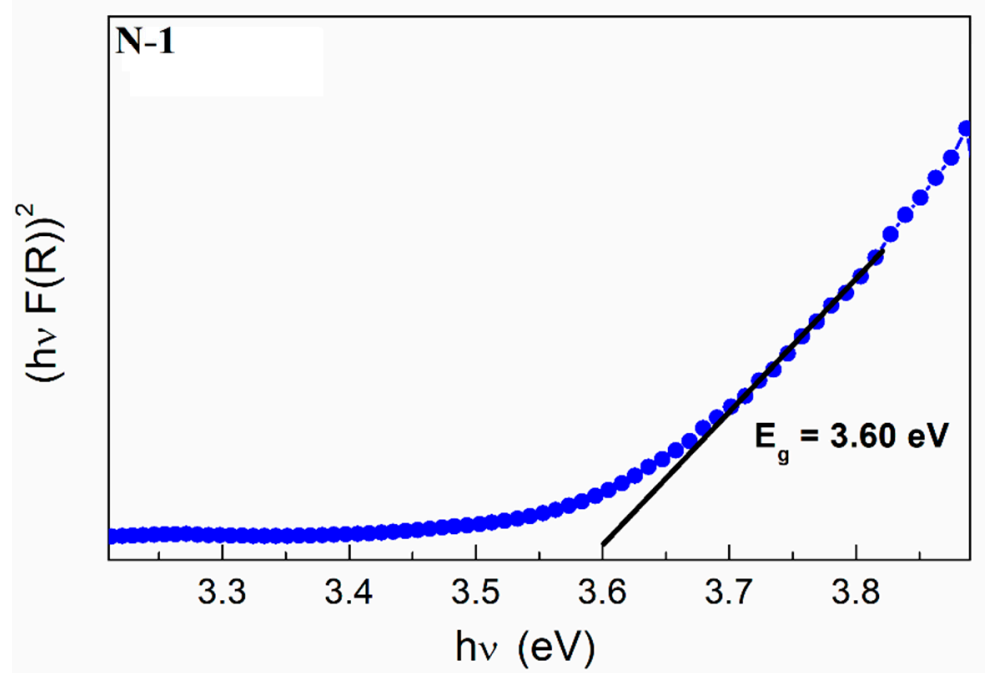

Figure 6. UV-Vis spectrum for N-1, N-2, and N-3 samples.

\subsection{Magnetic Properties}

We measured the magnetization (M) of all three $\mathrm{N}-1, \mathrm{~N}-2$, and $\mathrm{N}-3$ samples as a function of externally applied magnetic field $(\mathrm{H})$ at room temperature. Figure 7 shows the set of hysteresis loops of nickel oxide (i.e., N-1, N-2, and N-3). From the M-H curve, we have found an interesting fact that the magnetization value is invariably decreased with a rise in the calcination temperature. However, the coercivity is increased gradually as the calcination temperature increases (inset of Figure 7).

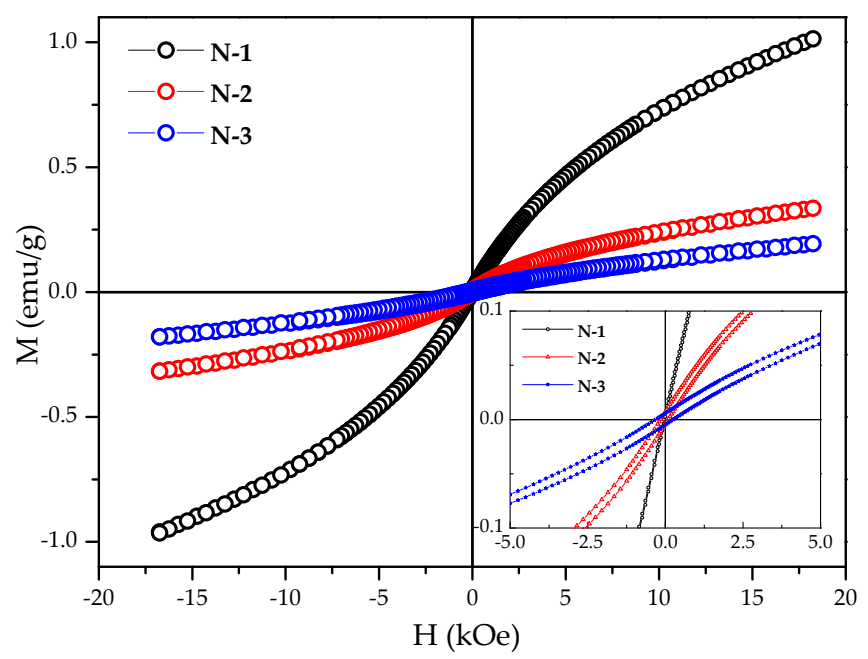

Figure 7. Room temperature obtained Magnetic (M-H) curves of $\mathrm{NiO}$ samples calcined at $350{ }^{\circ} \mathrm{C}$, $550{ }^{\circ} \mathrm{C}$, and $650{ }^{\circ} \mathrm{C}$ for $5 \mathrm{~h}$.

It is well known that the bulk $\mathrm{NiO}$ has an antiferromagnetic nature [44]. Nevertheless, despite being antiferromagnetic, the N-1 sample obtained after calcination at $350{ }^{\circ} \mathrm{C}$ for $5 \mathrm{~h}$ shows the weak ferromagnetic component at room temperature in the lower applied field. It is attributed to the small crystallite size and the increasing tendency of uncompensated spins. The very low magnetization value of N-2 and N-3 samples could be attributed to the observed superparamagnetism in nickel oxide, as well as the contribution towards the magnetic moment arising from other sources, such as the presence of non-stoichiometry and/or $\mathrm{Ni}^{3+}$ ions [45]. This means that the gradual increase in particle size of the polycrystalline $\mathrm{NiO}$ is the favorable condition for antiferromagnetic ordering (or spin compensation). 


\section{Conclusions}

In summary, we have investigated the effect of calcination temperature on structural, optical, and magnetic properties of $\mathrm{NiO}$. The $\mathrm{NiO}$ particles were synthesized by the chemical co-precipitation method. Structural characterization of the samples revealed cubic $\mathrm{NaCl}$ structure with $F m-3 m$ space group. Structural analysis also confirmed that the samples are free from any other impurity elements. The average crystalline size increases from $41 \mathrm{~nm}$ to above $100 \mathrm{~nm}$ as the calcination temperature increases. Spectral absorption bands were observed in $\sim 413,434$, and $444 \mathrm{~cm}^{-1}$ for $\mathrm{N}-1, \mathrm{~N}-2$, and $\mathrm{N}-3$ samples, respectively. The bandgap energy values for $\mathrm{N}-1, \mathrm{~N}-2$, and $\mathrm{N}-3$ samples are 3.60, 3.57, and $3.41 \mathrm{eV}$ respectively. The bandgap values decrease from $3.6 \mathrm{eV}$ to $3.41 \mathrm{eV}$ as the calcination temperature increases.

Author Contributions: Conceptualization, S.R. and H.C.N.; methodology, S.D., H.C.N. and S.R.; validation, S.D., S.S.P. and R.P.K.; formal analysis, investigation, and data curation, S.S.P., S.D., R.P.K. and H.C.N.; resources, H.C.N., S.S.P., S.D. and R.P.K.; writing-original draft preparation, S.D., S.S.P., R.P.K. and H.C.N.; writing-review and editing, S.R., S.S.P. and H.C.N.; supervision, funding acquisition, and project administration, R.P.K., H.C.N. and S.R. All authors have read and agreed to the published version of the manuscript.

Funding: This research received no external funding.

Data Availability Statement: The data presented in this study are available on request from the corresponding author.

Acknowledgments: Authors gratefully acknowledged T. Shripathi, V.G. Sathe, and M. Gupta UGCDAE CSR, Indore for providing characterization facilities.

Conflicts of Interest: The authors declare no conflict of interest.

\section{References}

1. Ghosh, S.K. Diversity in the family of manganese oxides at the nanoscale: From fundamentals to applications. ACS Omega 2020, 5, 25493-25504. [CrossRef] [PubMed]

2. Tanaka, M. Recent progress in ferromagnetic semiconductors and spintronics devices. Jpn. J. Appl. Phys. 2021, 60, 010101. [CrossRef]

3. Kannan, K.; Radhika, D.; Sadasivuni, K.K.; Reddy, K.R.; Raghu, A.V. Nanostructured metal oxides and its hybrids for photocatalytic and biomedical applications. Adv. Colloid Interface Sci. 2020, 281, 102178. [CrossRef] [PubMed]

4. Varshney, D.; Dwivedi, S. Synthesis, structural, Raman spectroscopic and paramagnetic properties of Sn doped NiO nanoparticles. Superlattices Microstruct. 2015, 86, 430-437. [CrossRef]

5. Li, L.; Chen, L.; Qihe, R.; Li, G. Magnetic crossover of NiO nanocrystals at room temperature. Appl. Phys. Lett. 2006, 89, 134102. [CrossRef]

6. Arif, M.; Sanger, A.; Shkir, M.; Singh, A.; Katiyar, R.S. Influence of interparticle interaction on the structural, optical and magnetic properties of $\mathrm{NiO}$ nanoparticles. Phys. B Condens. Matter 2019, 552, 88-95. [CrossRef]

7. Kote, J.R.; Kadam, A.S.; Ubaidullah, M.; Al-Enizi, A.M.; Al-Abdrabalnabi, M.A.; Nafady, A.; Imran, M.; Mane, R.S. Antimycobacterial, Antioxidant and Cytotoxicity Activities of Mesoporous Nickel Oxide Nanoparticles for Healthcare. Coatings 2020, 10, 1242. [CrossRef]

8. Bala, N.; Gupta, G.; Mitra, A.; Rath, S. Annealing effects on the microstructure, stoichiometry, and ferromagnetic/antiferromagnetic fraction in $\mathrm{NiO}$ nanoparticles. Mater. Sci. Eng. B 2021, 274, 115459. [CrossRef]

9. Jafari, A.; Jahromi, S.P.; Boustani, K.; Goh, B.T.; Huang, N.M. Evolution of structural and magnetic properties of nickel oxide nanoparticles: Influence of annealing ambient and temperature. J. Magn. Magn. Mater. 2019, 469, 383-390. [CrossRef]

10. Vijaya, J.J.; Kennedy, L.J.; Sekaran, G.; Nagaraja, K.S. Sol-gel derived (Sr, $\mathrm{Ni} \mathrm{Al}_{2} \mathrm{O}_{4}$ composites for benzene and toluene sensors. Mater. Lett. 2007, 61, 5213-5216. [CrossRef]

11. Kruefu, V.; Wisitsoraat, A.; Phokharatkul, D.; Tuantranont, A.; Phanichphant, S. Enhancement of p-type gas-sensing performances of $\mathrm{NiO}$ nanoparticles prepared by precipitation with $\mathrm{RuO}_{2}$ impregnation. Sens. Actuators B 2016, 236, 466-473. [CrossRef]

12. Azurdia, J.A.; Marchal, J.; Shea, P.; Sun, H.; Pan, X.Q.; Laine, R.M. Liquid-feed flame spray pyrolysis as a method of producing mixed-metal oxide nanopowders of potential interest as catalytic materials. nanopowders along the $\mathrm{NiO}_{-} \mathrm{Al}_{2} \mathrm{O}_{3}$ tie line including $(\mathrm{NiO})_{0.22}\left(\mathrm{Al}_{2} \mathrm{O}_{3}\right)_{0.78}$, a new inverse spinel composition. Chem. Mater. 2006, 18, 731-739. [CrossRef]

13. Amini, M.M.; Torkian, L. Preparation of nickel aluminate spinel by microwave heating. Mater. Lett. 2002, 57, 639-642. [CrossRef]

14. Loginova, E.; Cosandey, F.; Madey, T.E. Nanoscopic nickel aluminate spinel $\left(\mathrm{NiAl}_{2} \mathrm{O}_{4}\right)$ formation during $\mathrm{NiAl}(111)$ oxidation. Surf. Sci. 2007, 601, L11-L14. [CrossRef] 
15. Rahman, M.A.; Radhakrishnan, R.; Gopalakrishnan, R. Structural, optical, magnetic and antibacterial properties of Nd doped $\mathrm{NiO}$ nanoparticles prepared by co-precipitation method. J. Alloys Comp. 2018, 742, 421-429. [CrossRef]

16. Jeevanandam, P.; Koltypin, Y.; Gedanken, A. Preparation of nanosized nickel aluminate spinel by a sonochemical method. Mater. Sci. Eng. B 2002, 90, 125-132. [CrossRef]

17. Weidenthaler, C.; Schmidt, W. Thermal stability and thermal transformations of $\mathrm{Co}^{2+}-$ or $\mathrm{Ni}^{2+}$-exchanged zeolites $\mathrm{A}, \mathrm{X}$, and $\mathrm{Y}$. Chem. Mater. 2000, 12, 3811-3820. [CrossRef]

18. Tiwari, S.D.; Rajeev, K.P. Magnetic properties of NiO nanoparticles. Thin Solid Film. 2006, 505, 113-117. [CrossRef]

19. Bødker, F.; Hansen, M.F.; Koch, C.B.; Mørup, S. Particle interaction effects in antiferromagnetic NiO nanoparticles. J. Magn. Magn. Mater. 2000, 221, 32-36. [CrossRef]

20. Kodama, R.H. Magnetic nanoparticles. J. Magn. Magn. Mater. 1999, 200, 359-372. [CrossRef]

21. Winkler, E.; Zysler, R.D.; Mansilla, M.V.; Fiorani, D.; Rinaldi, D.; Vasilakaki, M.; Trohidou, K.N. Surface spin-glass freezing in interacting core-shell NiO nanoparticles. Nanotechnology 2008, 19, 185702. [CrossRef] [PubMed]

22. Tiwari, S.D.; Rajeev, K.P. Signatures of spin-glass freezing in NiO nanoparticles. Phys. Rev. B 2005, 72, 104433. [CrossRef]

23. Ba-Abbad, M.M.; Chai, P.V.; Takriff, M.S.; Benamor, A.; Mohammad, A.W. Optimization of nickel oxide nanoparticle synthesis through the sol-gel method using Box-Behnken design. Mater. Des. 2015, 86, 948-956. [CrossRef]

24. Jahromi, S.P.; Pandikumar, A.; Goh, B.T.; Lim, Y.S.; Basirun, W.J.; Lim, H.N.; Huang, N.M. Influence of particle size on performance of a nickel oxide nanoparticle-based supercapacitor. RSC Adv. 2015, 5, 14010-14019. [CrossRef]

25. Shanaj, B.R.; John, X.R. Effect of calcination time on structural, optical and antimicrobial properties of nickel oxide nanoparticles. J. Theor. Comput. Sci. 2016, 3, 149-159.

26. Karthik, K.; Selvan, G.K.; Kanagaraj, M.; Arumugam, S.; Jaya, N.V. Particle size effect on the magnetic properties of NiO nanoparticles prepared by a precipitation method. J. Alloys Comp. 2011, 509, 181-184. [CrossRef]

27. Wongsaprom, K.; Maensiri, S. Synthesis and room temperature magnetic behavior of nickel oxide nanocrystallites. Chiang Mai J. Sci. 2013, 40, 99-108.

28. Chatterjee, S.; Ray, A.; Mandal, M.; Das, S.; Bhattacharya, S.K. Synthesis and Characterization of CuO-NiO Nanocomposites for Electrochemical Supercapacitors. J. Mater. Eng. Perform. 2020, 29, 8036-8048. [CrossRef]

29. Dharmaraj, N.; Prabu, P.; Nagarajan, S.; Kim, C.H.; Park, J.H.; Kim, H.Y. Synthesis of nickel oxide nanoparticles using nickel acetate and poly (vinyl acetate) precursor. Mater. Sci. Eng. B 2006, 128, 111-114. [CrossRef]

30. Liu, D.; Li, D.; Yang, D. Size-dependent magnetic properties of branchlike nickel oxide nanocrystals. AIP Adv. 2017, 7, 015028. [CrossRef]

31. Ravikumar, P.; Kisan, B.; Perumal, A. Enhanced room temperature ferromagnetism in antiferromagnetic NiO nanoparticles. AIP Adv. 2015, 5, 087116. [CrossRef]

32. Duan, W.J.; Lu, S.H.; Wu, Z.L.; Wang, Y.S. Size effects on properties of NiO nanoparticles grown in alkalisalts. J. Phys. Chem. C 2012, 116, 26043-26051. [CrossRef]

33. Patel, K.N.; Deshpande, M.P.; Chauhan, K.; Rajput, P.; Gujarati, V.P.; Pandya, S.; Sathe, V.; Chaki, S.H. Effect of Mn doping concentration on structural, vibrational and magnetic properties of NiO nanoparticles. Adv. Powder Tech. 2018, 29, $2394-2403$. [CrossRef]

34. Ariyanta, H.A.; Ivandini, T.A.; Yulizar, Y. Novel NiO nanoparticles via phytosynthesis method: Structural, morphological and optical properties. J. Mol. Struct. 2021, 1227, 129543. [CrossRef]

35. Dubey, P.; Kaurav, N.; Devan, R.S.; Okram, G.S.; Kuo, Y.K. The effect of stoichiometry on the structural, thermal and electronic properties of thermally decomposed nickel oxide. RSC Adv. 2018, 8, 5882-5890. [CrossRef]

36. Zhang, W.B.; Hu, Y.L.; Han, K.L.; Tang, B.Y. Pressure dependence of exchange interactions in NiO. Phys. Rev. B 2006, 74, 054421. [CrossRef]

37. Soriano, L.; Preda, I.; Gutiérrez, A.; Palacín, S.; Abbate, M.; Vollmer, A. Surface effects in the Ni 2 p X-ray photoemission spectra of NiO. Phys. Rev. B 2007, 75, 233417. [CrossRef]

38. Mossanek, R.J.O.; Domínguez-Cañizares, G.; Gutiérrez, A.; Abbate, M.; Díaz-Fernández, D.; Soriano, L. Effects of Ni vacancies and crystallite size on the $\mathrm{O} 1 \mathrm{~s}$ and Ni 2p x-ray absorption spectra of nanocrystalline NiO. J. Phys. Condens. Matter 2013, $25,495506$. [CrossRef]

39. Tyuliev, G.; Sokolova, M. Temperature dependence of $\mathrm{Ni}^{3+}$ quantity in the surface layer of NiO. Appl. Surf. Sci. 1991, 52, 343-349. [CrossRef]

40. Landi, S.; Segundo, I.R.; Freitas, E.; Vasilevskiy, M.; Carneiro, J.; Tavares, C.J. Use and misuse of the Kubelka-Munk function to obtain the band gap energy from diffuse reflectance measurements. Solid State Comm. 2021, 114573. [CrossRef]

41. Li, Q.; Xie, R.; Li, Y.W.; Mintz, E.A.; Shang, J.K. Enhanced visible-light-induced photocatalytic disinfection of E. coli by carbonsensitized nitrogen-doped titanium oxide. Environ. Sci. Technol. 2007, 41, 5056. [CrossRef] [PubMed]

42. Kislov, N.; Srinivasan, S.S.; Emirov, Y.; Stefanakos, E.K. Optical absorption red and blue shifts in $\mathrm{ZnFe}_{2} \mathrm{O}_{4}$ nanoparticles. Mat. Sci. Eng. B 2008, 153, 70-77. [CrossRef]

43. Kale, R.B.; Lokhande, C.D. Influence of air annealing on the structural, optical and electrical properties of chemically deposited CdSe nano-crystallites. Appl. Surf. Sci. 2004, 223, 343-351. [CrossRef] 
44. Sugiyama, I.; Shibata, N.; Wang, Z.; Kobayashi, S.; Yamamoto, T.; Ikuhara, Y. Ferromagnetic dislocations in antiferromagnetic NiO. Nat. Nanotech. 2013, 8, 266-270. [CrossRef]

45. Deraz, N.M. Magnetic behavior and physicochemical properties of Ni and NiO nano-particles. Curr. Appl. Phys. 2012, 12, 928-934. [CrossRef] 